\title{
A Review of Use of eLearning in Pharmacology
}

\section{Ashwin Kamath.}

Department of Pharmacology, Kasturba M edical College, M anipal University, M angaluru, Karnataka, India.

\section{ABSTRACT}

Teaching in pharmacology is predominantly lecture based. While practical sessions do include problem solving and case scenarios the teaching methodologies are inadequate in empowering the students to handle real life scenarios which require integration of theory and practice, application of knowledge and skills to find a viable solution to a defined problem. Use of elearning in such situations is still in its infancy in Indian medical colleges and thus provides a unique opportunity to improve the existing teaching and learning methods. This review will look into studies describing various forms of elearning methodologies adopted for teaching pharmacology to health professionals as well as those which have tried to assess the effect of elearning approach adopted in teaching pharmacology across the globe.

KEY WORDS: eLearning, Pharmacology, teaching, Lectures, Teaching methodologies.

Address for correspondence: Dr. Ashwin Kamath, Department of Pharmacology, Kasturba M edical College, M anipal University, M angaluru, Karnataka, India. E-Mail: ashwin.kamath@ manipal.edu

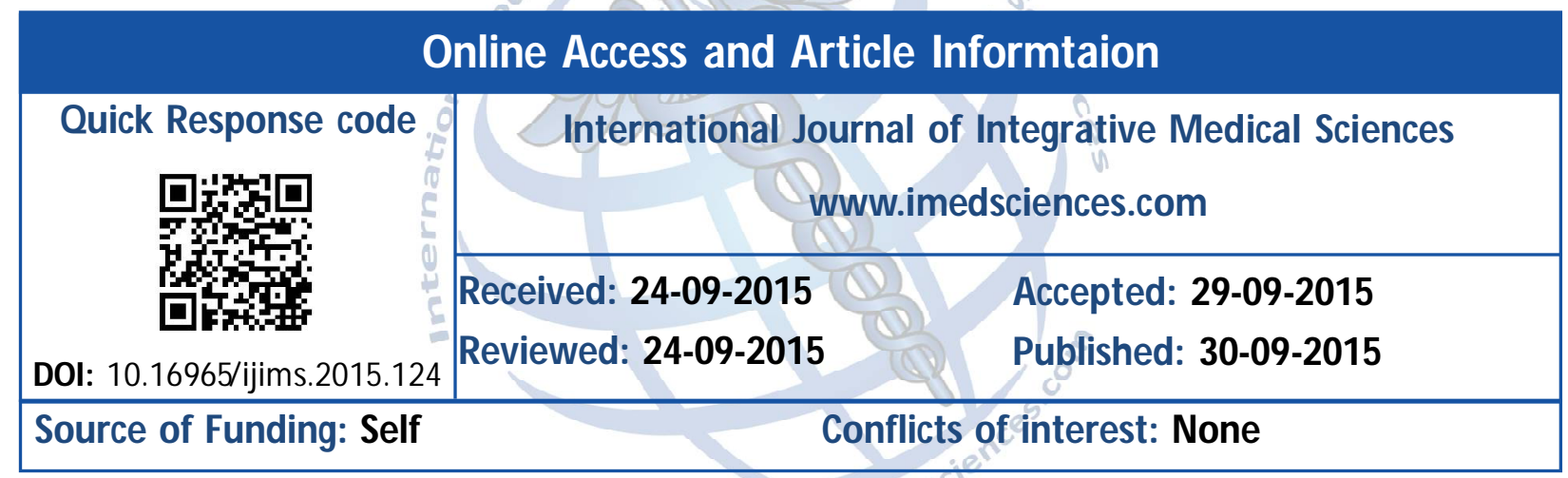

\section{INTRODUCTION}

As per the regulations of graduate medical education of India, pharmacology is taught during the second year of the medical course before the commencement of the clinical subjects. Graduate medical curriculum is oriented towards training students to undertake the responsibilities of a physician of first contact who is capable of looking after the preventive, curative and rehabilitative aspect of medicine [1]. Acquiring adequate knowledge about drugs is one of the preliminary steps in preparing the medical student for future practice. It is important that the students appreciate the importance of pharmacology and learn to apply that knowledge appropriately in a given clinical context [2]. Teaching in pharmacology is predominantly lecture based. While practical sessions do include problem solving and case scenarios the teaching methodologies are inadequate in empowering the students to handle real life scenarios which require integration of theory and practice, application of knowledge and skills to find a viable solution to a defined problem. Undergraduate pharmacology teaching should stress the principle of rational evaluation of therapeutic alternatives and developing a personal formulary on the basis of a rational comparison. Such exercises would help students identify extraneous factors that could affect their ability to prescribe rationally [3]. Solving real life scenarios, rather than decontextualized learning activities or problems designed to elicit only recollection of factual knowledge, promotes high level thinking and encourages students to acquire answers from different resources that they may access as 
professionals. The opportunity to apply knowledge and concepts through problem-solving for real world issues offers students contextualized learning and a powerful learnercentered instructional approach [4]. Use of eLearning in such situations is still in its infancy in Indian medical colleges and thus provides a unique opportunity to improve the existing teaching and learning methods. elearning may be defined as "an approach to teaching and learning, representing all or part of the educational model applied, that is based on the use of electronic media and devices as tools for improving access to training, communication and interaction and that facilitates the adoption of new ways of understanding and developing learning" [5]. The World Health Organization recognizes elearning to be of high relevance in resource poor countries with chronic lack of educated staff [6]. A full or complete eLearning approach is defined as learning with no faceto-face component that relies entirely on the use of eLearning technology and techniques for its delivery. This would overcome the geographic and time constraints involved in delivery of learning materials besides the decrease in manpower requirement [5]. What is more likely to occur in medical institutions is adoption of a blended approach which is a mix of traditional and fully online methodologies. In fact, the attempt to incorporate electronic technology for knowledge delivery is not of recent origin. Both, at an individual and institutional level, adoption of various forms of eLearning methodologies are being attempted from more than a decade. However, increasing web literacy and easy, affordable access to necessary hardware has reemphasized the need for eLearning in medical education systems. This review will look into studies describing various forms of eLearning methodologies adopted for teaching pharmacology to health professionals as well as those which have tried to assess the effect of elearning approach adopted in teaching pharmacology across the globe.

eLearning methods in teaching pharmacology: A number of studies have been conducted over the past two decades to assess elearning in pharmacology. Brain et al assessed the effect of a computer based teaching program effect of a computer based teaching program on pharmacology and pathophysiology of inflammation among 78 second year medical students [7]. While the program was found to be effective in terms of increase in knowledge it was also opined by students that such program should complement rather than replace traditional lectures. This could partly be because of the way the course was developed and the time constraints because of which the students were unable to complete the course in their own pace [7]. Another early attempt for assessment of eLearning in pharmacology comes from the study of Dewhurst et al [8]. The objective of the study was to test a strategy to facilitate teacher's use of existing elearning resources in pharmacology. The eLearning resources were developed by pharmacologists as a part of UK government funded initiative. These elearning resources could be modified by the end users (teachers) as per their needs. Preliminary evaluation of data from students and pharmacology teachers showed that it was generally acceptable to both. From a student's perspective, the most important aspect recognized was the flexibility offered by this mode of learning. However, they valued contact with a tutor and were of the view that it should supplement rather than replace traditional teaching. In fact, over $50 \%$ of the students found independent learning to be less interesting than traditional lectures. From the teacher's perspective, the project enabled them to use preexisting eLearning resources developed by subject experts thereby saving time and also making eLearning more acceptable. However the number of pharmacology teachers who responded for the evaluation was small in number to draw any significant conclusions. Efferth et al describes the experience of incorporating an elearning lecture series on cancer biology and pharmacology as an optional offering to the existing curriculum for molecular biology and pharmacy students over a ten years period [9]. This elearning program involved a twelve lecture series consisting of PowerPoint slides synchronized with a video track using $M$ icrosoft Producer which could be downloaded by the consenting students. A questionnaire was to be answered at the end of the lectures to ensure 
the students had listened to the lecture. A total of 317 students participated over ten years. Overall, the general impression about material provided was positive, students intended to continue with eLearning and also recommend it to their friends. They also wanted more of such eLearning to be incorporated into their curriculum. Tse et al describes the assessment of a web-based eLearning course for first year nursing students which integrated pathophysiology of important systemic diseases to pharmacology of 150 commonly used drugs [10]. The course was perceived by students to encourage understanding of subject rather than rote learning while also develop problem solving and critical thinking abilities. The time flexibility and convenience associated with web-based learning was another important advantage of the eLearning course as perceived by the students. The study by Franson et al is important in terms of the evaluation methodology adopted [11]. The objective of the study was to determine whether student use of a computer based clinical pharmacology learning program relates to final examination grades. The clinical pharmacology database consisted of schematic graphics using a unique icon language, explanation texts and feedback questions to explain pharmacology as it pertains to pathophysiology for all relevant topics. Since the program was noncompulsory, it was to be determined whether students actually benefited from it. The evaluation was based on the final examination grades (summative assessment) as it is a good predictive factor for success on medical examinations and of clinical performance. Majority of the students used the program particularly as the examinations approached indicating that the program was perceived to be a good study tool. The time spent using the program showed that increased use by an individual student was associated with a small increase in grade. Students with poorer exam scores appeared to derive a larger benefit, although, those with higher than average exam scores logged in to the program more frequently. In contrast to the above studies which mainly targeted students, an interactive elearning course designed to improve the understanding of pharmacokinetics principles among scientists carrying out therapeutic drug monitoring found favorable outcome in terms of understanding the subject [12]. However, the course did not result in better interpretation of the lab results. Subjectively, the participants found the resource easy to use and navigate.

Kim et al have tested an online, supplementary pharmacology curriculum (fourteen self-paced modules) which included a topic introduction, reading assignment, and self-assessment quiz for first year medical students with satisfactory results [13]. Baskett developed a National Prescribing Curriculum for health professionals which would help learners build their own personal formulary for specific conditions enabling them to prescribe confidently and rationally [14]. The online self-paced modules were developed using a learning activity management system software. The contents of the modules were based on the World Health Organization guide to good prescribing. The course not only mimics the real life scenarios but also enables reviews from tutors as well as peers. Rosenbaum et al describe the experience of a blended course design consisting of five week postgraduate course in clinical pharmacology for postgraduate dental students with 15 hours of lectures and online learning activities [15]. Sucha et al describes the use of internet discussion forums moderated by final year medical students to enhance student centered pharmacology learning [16]. Zollner et al describe the generation of high-quality e-learning content in a student-centered and interdisciplinary manner [17]. They developed a peer-teaching concept in which e-learning cases of clinical pharmacology were independently researched and written by finalyear medical students with the elective pharmacology. The cases were subjected to multi-step peer review and published on the open-access internet platform. Gaikwad et al evaluated the effectiveness and acceptability of an interactive eLearning module in endocrine pharmacology among second year medical students [18]. Pre and post test scores showed that the intervention was moderately effective although there was also a high attrition rate. However, the course was well received by those 
who completed the entire exercise. Karaksha et al evaluated the effectiveness of a supplemental eLearning pharmacology course which was integrated with the regular course in third year undergraduate pharmacy students [19]. It basically consisted of a suite of 143 eLearning tools focusing on drug mechanisms of action complementing the existing curriculum. Bloom's revised taxonomy and structure of the observed learning outcome (SOLO) taxonomy were used to analyse student level of understanding and evaluate the effect of eLearning tools.

eLearning methods in practical pharmacology: Computer assisted learning (CAL) predates the widespread availability of internet. A CAL program is usually run from a CD ROM, floppy disk or local area network to deliver a subject specific, interactive, multimedia learning experience. The use of computer based alternatives to animal use in practical pharmacology began in the early 1980 's $[20,21]$. A number of studies have described the usefulness of these computer based alternatives, particularly among medical students majority of whom do not require animal handling skills in the future [22-28], apart from the obvious ethical and economical concerns involved. Also important is the fact that such simulated experiments can be repeated as many number of times as required, by multiple students at the same time while the responses to different drugs or drug doses are preset and undesired response variations are avoided. The use of CAL in pharmacology practicals have mainly involved demonstration of effect of drugs on isolated tissues and autonomic responses. The usefulness and acceptability of such programs is to a large extent based on its implementation and assessment. A study of computer simulated pharmacology experiments in undergraduate pharmacy students in an Australian university showed that the integration of experiments in the regular timetable, stating of clear objectives and tasks and presence of a teacher helped avoid user fatigue and frustration [29].

Perceived advantages and disadvantages of eLearning systems: A number of studies on elearning methods have focused on obtaining feedback from teachers and students on its suitability and acceptability.
The advantages and disadvantages expressed in the individual studies are influenced by a number of factors such as: a) the mode of elearning (slides with embedded audio narration, slide presentation with videos and graphics, interactive presentation requiring user inputs etc) b) content of presentation (learning objectives stated or not, too much factual content, predominantly text content) c) initial enthusiasm of the participants d) validity of the questionn-aire and other assessment methods used e) whether the eLearning program was part of the curriculum or only an experimental exercise. However, notwithstanding the above factors, the views obtained from various studies can be used to improve the existing elearning systems or considered while developing new eLearning content.

The perceived advantages of eLearning are as follows:

1. The most important advantage of elearning as perceived by the end users has been the possibility of self-paced learning without the constraints of time and space $[8,12$, $15,16]$.

2. Students perceive eLearning systems easy to use and many interlinked subject matter can be presented and learnt in a comprehensive manner $[7,15,18]$.

3. in elearning contents can be accessed or provided to users on an as and when required basis [15]. Hence, the students can access the learning content again and again to obtain increasing clarity on the content. This is in contrast to a lecture where the students have to ensure that they derive the maximum benefit from a lecture session which, very often, will not be repeated.

4. Interdisciplinary learning content can be easily delivered $[9,17]$. While the initial preparation of learning content can be time consuming and requires coordination between the content developers from various departments, once prepared the content can be easily delivered and reused.

5. The content can be designed to reinforce understanding of dynamic processes and provide clear visuals of drug mechanisms and interactions. eLearning can also be 
used to develop problem solving and critical thinking abilities $[8,10]$.

6. elearning modules which contain discussion forums and allow for user interaction makes it possible for users to access older posts and discussions [16]. This can help in gaining deeper understanding of the subject or clarification of doubts.

7. When contents can be accessed in the absence of physical presence of teachers or peers, it can result in a lower inhibition threshold for asking questions and encourage healthy debate which can enhance learning [16].

The perceived disadvantages of eLearning are as follows:

1. elearning content if not properly designed could turn out to be too lengthy and overloaded with information $[7,8]$. Uncluttered presentation of information, delivery of information in a sequential manner based on increasing complexity etc needs to be planned out during the content generation phase. Similarly, periodic modification of content based on user feedback is also essential.

2. Potential loss of contact with tutors could be a limiting factor [8]. This would again depend on the context in which elearning is being used and whether it is being used to completely replace the physical presence. of a tutor.

3. Lack of clarity about learning objectives could lead to underutilization of the eLearning resource [8].

4. Lack of adequate infrastructure for delivery of elearning content, particularly web based contents which require adequate internet connectivity and hardware could be a limiting factor in some areas [18].

5. From a teacher's perspective, the time and effort required to initially develop the contents and lack of adequate knowledge and resources regarding the same is an important limitation [8].

\section{CONCLUSION}

The current teaching and learning scenario, particularly in India, provides ample scope for incorporation of elearning methods for knowledge delivery. While initially the teachers will have to be trained in handling eLearning systems and significant time needs to be dedicated to learning content development the efforts would be amply rewarded by the subsequent advantages of a well-developed eLearning module. At the same time it is to be remembered that elearning is only a method of content delivery. Its usefulness is dependent on its content and how it is presented. Excess content delivery, lack of clear learning objectives, using learning material easily available from text books without any explanatory information etc will discourage students from utilizing the elearning resource and also defeat the very purpose of providing contextualized learning. Integration of audio and video files with text materials, enabling user inputs and tasks for assessment, presentation of interdisciplinary concepts and sequential presentation of learning content of increasing complexity for selfdirected learning independent of time and space constraints provides an excellent platform to deliver problems based on real life scenarios. Hence, elearning is an important teaching and learning approach which will help achieve the undergraduate pharmacology teaching objectives.

\section{REFERENCES}

[1]. Salient features of Regulations on Graduate M edical Education, 1997 (Internet). 1997. Published in part iii, section 4 of the Gazette of India dated 17th M ay 1997. [http://www.mciindia.org/Rules and Regulations/Graduate Medical Education Regulations1997.aspx]

[2]. Rangachari PK. Basic Sciences in an Integrated Medical Curriculum: The Case of Pharmacology. Adv Health Sci Educ Theory Pract. 1997;2(2):163171.

[3]. Upadhyaya P, Seth V, Sharma M, Ahmed M, M oghe VV, Khan ZY et al. Prescribing knowledge in the light of undergraduate clinical pharmacology and therapeutics teaching in India: views of first-year postgraduate students. Adv M ed Educ Pract. 2012 Jun 5;3:47-53.

[4]. Galea V, Stewart T, Steel CH. Challenge FRAP: An elearning tool used to scaffold authentic problemsolving processes. Proceedings ascilite Singapore 2007. [http://www.ascilite.org.au/conferences/ singapore $07 /$ procs/galea.pdf]

[5]. Imperial College London, World Health Organization. eLearning for undergraduate health professional education: a systematic review infor- 
ming a radical transformation of health workforce development. Jan 2015. [http://who educationguidelines.org/content/eLearning-report]

[6]. Suarez-Kurtz G. Comments to the IUPHAR document on clinical pharmacology. World Health Organization. [http://www.who.int/ selection_medicines/committees/expert/18/policy/ Kurtz_Bräzil_IUPHAR.pdf]

[7]. Brain $S$, Dewhurst D, Williams A. Evaluation of the usefulness of a computer based learning program to support student learning in pharmacology. ALT-J. 1999; 7:37-45.

[8]. Dewhurst D G, Norris TAM. Helping teachers to embed e-learning materials into undergraduate pharmacology courses. Bioscience Education. 2003;1(1). DOI: 10.3108/beej.2003.01010006

[9]. Efferth T. Ten Years' Experience with an E-Learning Lecture Series on Cancer Biology and Pharmacology. Educ. Sci. 2013;3:1-16.

[10]. Tse M M, Lo LW. A Web-based e-learning course: integration of pathophysiology into pharmacology. Telemed J E Health. 2008;14(9):919-24.

[11].Franson KL, Dubois EA, de Kam ML, Cohen AF. M easuring learning from the TRC pharmacology ELearning program. $\mathrm{Br}$ J Clin Pharmacol. 2008;66(1):135-41.

[12].Samani K. Therapeutic drug monitoring: an elearning resource. Bioscience Horizons. 2009;2(2):113-124.

[13]. Kim PY, Allbritton DW , Keri RA, M ieyal JJ, WilsonDelfosse AL. Participation in supplemental online pharmacology modules results in learning gains and student engagement [abstract]. Medical Science Educator 2010;20(2s).

[14]. Baskett K. Using e-learning to improve prescribing practice in emerging prescribers. Teaching English with Technology - Special Issue on LAMS and Learning Design. 2011;11(1):98-109.

[15]. Rosenbaum PE, Mikalsen O, Lygre $H$, Solheim E, Schjøtt J. A Blended Learning Course Design in Clinical Pharmacology for Post-graduate Dental Students. Open Dent J. 2012;6:182-7.

[16].Sucha M, Engelhardt S, Sarikas A. Internet discussion forums as part of a student-centred teaching concept of pharmacology. GMS Z Med Ausbild. 2013;30(1):Doc2.

[17]. Zollner B, Sucha M, Berg C, M uß N, Amann P, AmannNeher B, Oestreicher D, Engelhardt S, Sarikas A. Pharmacases.de - a student-centered e-learning project of clinical pharmacology. Med Teach. 2013;35(3):251-3.

[18]. Gaikwad N, Tankhiwale S. Interactive E-learning module in pharmacology: a pilot project at a rural medical college in India. Perspect M ed Educ. 2014 Jan;3(1):15-30.
[19]. Karaksha A, Grant G, Nirthanan SN, Davey AK, Anoopkumar-Dukie S. A Comparative Study to Evaluate the Educational Impact of E-Learning Tools on Griffith University Pharmacy Students' Level of Understanding Using Bloom's and SOLO Taxonomies. Education Research International. 2014;2014:1.

[20]. E Hughes I. Computer-based learning-an aid to successful teaching of pharmacology? Naunyn Schmiedebergs Arch Pharmacol. 2002;366(1):7782.

[21]. Dewhurst D. Computer-based alternatives in higher education-past, present and future. ALTEX. 2006;23(3):197-201.

[22]. Dew hurst DG, Hardcastle J, Hardcastle PT, Stuart E. Comparison of a computer simulation program and a traditional laboratory practical class for teaching the principles of intestinal absorption. Am J Physiol. 1994;267:S95-104.

[23]. Dew hurst D. Computer-based alternatives to using animals in teaching physiology and pharmacology to undergraduate students. Altern Lab Anim. 2004 Jun;32 Suppl 1B:517-20.

[24]. Dewhurst D. Is it possible to meet the learning objectives of undergraduate pharmacology classes with non-animal models? AATEX. 2008;14:207-12.

[25]. Kuruvilla A, Ramalingam S, Bose AC, Shastri GV, Bhuvaneswari K, Amudha G. Use of computer assisted learning as an adjuvant to practical Pharmacology teaching: Advantages and limitations. Indian J Pharmacol. 2001;33:272-5.

[26]. Badyal DK, M odgill V, Kaur J. Computer simulation models are implementable as replacements for animal experiments. Altern Lab Anim. 2009;37:1915.

[27].Govindaraja C, Jaiprakash H, Annamalai C, Vedhavathy SS. Computer assisted learning : Perceptions and knowledge skills of undergraduate medical students in a Malaysian medical school.. Natl J Physiol Pharm Pharmacol. 2011;1(2):63-67.

[28]. Leathard H L, Dewhurst DG. Comparison of cost effectiveness of a computer assisted learning program with tutored demonstration to teach intestinal motility to medical students. ALT-J. 1995;3:118-25.

[29].Wang L. Computer-simulated pharmacology experimentsfor undergraduate pharmacy students: Experience from an Australian university. Indian J Pharmacol. 2001;33:280-2. 